\title{
Analysis of Military-civilian Integration Influence Factor for Chinese Unmanned Aerial Vehicle Industry
}

\author{
Liang JIANG \\ Institute of Economics Management Humanities and Social Science, Harbin Institute of Technology, \\ Harbin, Heilongjiang 150006, China \\ jliang126@126.com
}

Keywords: UAV, Military-civilian integration, Influence factors.

\begin{abstract}
Unmanned aerial vehicle (UAV) possesses the feature of multi-disciplinary synthesis. The technology development of UAV needs joint efforts come from military industrial enterprises, universities and private enterprise in all aspects. The widely application prospect in military-civilian makes the UAV industry having huge development spaces. In order to analyze the factors influencing military-civilian integration in the development of UAV industry, comprehensive analysis is carried out in this paper from the national level to enterprise level.
\end{abstract}

\section{Introduction}

In such important stage of economic transformation in China, the Party Central Committee has put forward a strategic decision to promote the economic development and to enhance the innovation capacity in the military-civilian integration. Military-civilian integration is to combine national defense science, technology and industry and civilian industry to form a unified national science and technology industry. Under the background of military-civilian integration, the action is composed of two aspects. On the one hand, the national defense science technology industry should be applied to civilian markets. On the other hand, the private industries and capitals should be merged into national science technology industrial system. The prospect of these two aspects is the formation of military-civilian integration pattern. As a new industry, UAV will become a major weapon in future battlefields. Meanwhile, UAV can also been widely used in scientific exploration, agriculture and forestry protection, electric power patrol, aviation photograph, environment monitoring, earthquake rescue, counter-terrorism, public security, and so on. Since the widely usages and close connection to multi-industrial fields, as well as rapid innovation speed, military-civilian integration has good prospects in the UAV industry.

\section{Characteristics of military-civilian integration in UAV industry}

The purpose of military-civilian integration is to promote the coordinated development of national defense construction and economic development. The complete national economic system can be thus formed. The core of such action is to improve innovation ability and technical level of relevant industries. Military-civilian integration is mainly related to three aspects. For one thing, with the full use of the advantages of R\&D resources, advanced manufacturing, assembly, integration, and scientific research faculties of military enterprises, the tasks of weapons and equipment development can be successfully completed. Meanwhile, the scientific research abilities of military enterprises can be devoted into the national economic system. The proportion of innovation economy in national economy system can also be promoted. For another, the advantages of flexible management mechanism, strong sensitivity, and wide coverage of the private enterprises can be fully used. With the utilization of resources advantages of private enterprises, the proportion of private capital and technologies in national economic system can be enhanced. Finally, the application in the UAV industry can be regarded as a perfect breakthrough point. The circumstance features of resource sharing, benefit competition and innovation will hence emerged.

As a high-technology product in the information age, UAV system has become an important symbol of the construction and informatization of national defense system all over the world. Many developed countries and emerging industrialized countries are attaching great importance to the research, 
development and application of UAVs. Since UAV is a complex and multidisciplinary system, its technology development not only depends on basic industry technologies, but also relies on the advanced innovation abilities. For example, raw materials, components, manufacturing are all involved in the basic technical abilities. Meanwhile, computer science, navigation technology, control algorithms, artificial intelligence, and 3-D printing are also been considered as advanced technical capabilities. The application areas of UAV are covering all aspects of military and civilian fields. For military application considerations, the UAV which deemed as useful reconnaissance equipment, have already been used in several local hot spots. Some kind of reconnaissance-strike UAVs have been successfully applied in the counterterrorism operations by US troops. With the improvement of the technologies, UAVs will be more wildly used in the occasions such as battlefield awareness, troops commanding, protection, and logistics tasks. In another word, UAVs will play more important roles and become the leading role in the future battlefield. For civilian application considerations, UAVs have been used for scientific exploration of hurricanes. In the aspect of resources, forestry, geology and offshore explorations, UAVs will play a greater role. UAVs also have unique advantages in the forest fire prevention, disaster prevention, rescue-relief coordination, and aviation mapping, etc.

Known from above, the development and technological progress of UAV industries will form the new pattern of military-civilian integration. Many fields will be closely connected. Basic industrial technology, advanced innovation and technology application are all good examples.

\section{Status of military-civilian integration of UAV}

During the development of unmanned aerial vehicle (UAV) equipment in our country, a series of laws, regulations and management system covering scientific research license, quality system, and confidentiality, has been launched. An industrial chain composed of military enterprise and some universities has been established. The development, production, testing, delivery and after-sale guarantee are all limited in this chain. On the contrary, the private enterprise and private capital is difficult to enter the military equipment system. Meanwhile, because the lack of relevant evaluation standards, large-scale application of UAV is hard to be realized in civilian fields such as public security, territorial resources, forestry, marine, electric power, petroleum, and meteorological. Besides, the UAVs promoted by most private enterprises are not only relatively simple, but also have some weaknesses in aspects such as reliability and security. Therefore, it is difficult to form an industrial development pattern for private enterprises. On the other hand, the insufficient analysis to the Imarket demand also restricts the expansion of military enterprises to the civilian market.

Influence factors of military-civilian integration in the UAV industry

The factors influencing of military-civilian integration in the UAV industry can be classified into two categories, i.e., national and enterprise level. At the national level, three aspects are concerned. The first one is policy guiding and supporting regulations. The second one is industrial standards and specifications. The last one is assessment and risk control. At the enterprise level, the management and operation mode is mainly concerned.

\section{Influence factors of military-civilian integration in the UAV industry}

The factors influencing of military-civilian integration in the UAV industry can be classified into two categories, i.e., national and enterprise level. At the national level, three aspects are concerned. The first one is policy guiding and supporting regulations. The second one is industrial standards and specifications. The last one is assessment and risk control. At the enterprise level, the management and operation mode is mainly concerned.

\section{The influence factors at the national level}

\section{Policy guiding and supporting regulations.}

1) Policy guidance

Policies are usually regarded as a major fact which influencing the innovation and development of UAV industry. However, policies can form an environment for the military-civilian integration, and 
further mobilize participants devote into the development of the UAV industry. Moreover, policies can also encourage improving the industry through technical innovation, and putting forward to eliminate technical barriers. In the aspects of military-civilian integration, our country has launched a series of policies. However, some more relevant guiding policies are still remains to be further introduced. These policies include national UAV industry planning, military/civilian equipment procurement management methods, low-altitude open management method for UAVs, etc.

2) Laws and regulations

The construction of laws and regulations affects the development of military-civilian integration of UAV industry. The processes, such as purchasing, design, manufacturing, service and guarantee, can all be well supervised. Meanwhile, orderly environment features of fair competition and fit-survive for military and civilian integration can be formed for the UAV industry. Our country has issued some legal documents, such as the intellectual property rights protection law, anti-improper competition law, and the patent law, etc. Nevertheless, as far as the implementation of these laws is concerned, supervision and punishment for infringement party is not strong enough. Consequently, the advancement of UAV is limited because of the blocking patent and technologies.

Standards and specifications. Standardization is an important factor affecting the design, manufacture, test, purchase, and application of UAVs. It is more important and necessary for the cases which UAVs fighting into the national airspace scope. As the scope is where the safety of other airplanes, people on the ground are seriously concerned. Only according with the unified standards and specification, UAVs can be widely applied in various fields. The standards and specification applied to UAVs mainly include the specifications relating with indexing system, airworthiness, reliability, security, test, acceptance, and product application.

Since of UAVs are multidisciplinary, the standard and specification system applied to UAVs require further decomposition into many detailed ones. Some important stand-alone equipment also needs standard and specification for restriction.

Assessment and risk control. In the premise of meeting the standards and specifications, an important factor in development of UAV industry is to establish a proper evaluation system. Only evaluation is carried out exactly, the effectiveness of the UAV can be maximized. This evaluation system should be performed by some independent agencies authorized by the government. All kinds of UAVs entering the national airspace should be evaluated.

Safety is an important factor which affecting the usage of UAVs. The risk management and control is particularly important when the UAV is malfunctioned or abnormal. However, the unsafe factors in the flight process can be fully minimized through reasonable risk managements.

\section{The influence factors at the enterprise level}

Through the development of military industry for many years, the military enterprises are strictly managed by the government involving many aspects, such as equipment permission, quality system, reliability, security, maintainability, testability, supportability, environmental adaptability, electromagnetic compatibility, etc. Moreover, the research procedure, which ranging from prospect demonstration, development, production, flight test pattern design, and final design to production, has already been specified. The military enterprises have formed a management system that accords with certain requirements. For management consideration, military enterprises are capable of covering the civilian market requirements. However, as far as the operation mode is concerned, the insufficiency of exploration, user requirement analysis and demanding guidance has strongly restricted the process of military-civilian integration.

Due to the willing of benefit maximization and the sense of survival crisis, private enterprises are extremely sensitive to the market demands. Therefore, most private enterprises adopt more flexible operation modes to facilitate merging into UAV civilian markets. Nevertheless, due to the isolation from the military equipment system, the management gap between the private enterprises and the equipment system cannot be ignored yet. The gap becomes an important factors which restricting the private enterprises merging into the military equipment system.

Enterprise cooperation is one of the reasonable solutions of military-civilian integration. The integration manner and profit distribution issues are important factors affecting the military-civilian 
integration in UAV field. How to fully protect the interests of all participants in the cooperation process is the most important factor which influences all enterprises to devote into the development of industrialization of UAV.

\section{Summary}

As a multi-disciplinary synthesis industry, the development of UAV needs joint efforts come both from military and civilian enterprise in all aspects. Meanwhile, the widely application prospect shows the huge development spaces of UAV industry. In this paper, comprehensive analysis is carried out from the national level to enterprise level to discuss and evaluate the influences to the military-civilian integration in the development of UAV industry. The three important factors lie in the national level are policy guiding, standards, and risk control. While the factors lie in the enterprise level are mainly concerned with integration manner and profit distribution issues. The results deduced in this paper will do some help to the development of UAV industry.

\section{References}

[1] S. F. Jiang, B. Yang, Q. H. Shen, Study on constructing coordinated innovation mechanism for military and civilian integration, Science \& Technology Progress and Policy, 31(2014)95-97.

[2] Z. Y. Song, Z. H. Su, G. Xu, Considerations of advancing our army's civil-military integration equipment logistics, Journal of Equipment Academy, 25(2014)43-46.

[3] J. G. Zhang, Analysis on the scientific connotation and times value of the civil-military integration development, Journal of Equipment Academy, 25(2014)9-13.

[4] Y. H. Guo, Analysis on technology innovation of civil-military integration from institutional view, Science and Technology Management Research, 3(2014)15-17.

[5] Y.Zhang, H. P. Li, Y. P. Yao, Research on the western China of civil military integration of industry optimal allocation of resources based on DEA, Science \& Technology Progress and Policy, 31(2014)89-93. 